\title{
Longitudinal neuropsychological evaluation of HIV-infected intravenous drug users
}

\author{
GIORGIO BONO, MARCO MAURI, ELENA SINFORIANI, \\ GIORGIO BARBARINI, ${ }^{1}$ LORENZO MINOLI $^{2} \&$ MAURIZIO FEA $^{2}$
}

\author{
Neuro AIDS-Unit, IRCCS C. Mondino, University of Pavia, Italy/'Department of Infectious \\ Diseases-IRCCS S. Matteo, University of Pavia, Italy $\mathcal{F}^{2}$ SERT USSL 77 Pavia, Italy
}

\begin{abstract}
The present study aimed to describe the cognitive status of a group of HIV-positive asymptomatic intravenous drug users (IVDU) and changes which occurred over a 12-month follow-up period. Forty-two HIV positive IVDU were selected and matched for age, sex, educational level and pattern of drug abuse with 39 seronegative IVDU controls. Baseline and follow-up evaluation included neuropsychological tests exploring attention, language, memory, logic and visuomotor abilities, biological markers and clinical parameters. About one-third of both seropositive and seronegative subjects showed at baseline slight cognitive deficits, 'which did not change during the follow-up period.
\end{abstract}

\section{Introduction}

Despite some previous controversial data, recent findings seem to suggest that there is some increase in the likelihood of detecting mild cognitive disorders in asymptomic HIV-infected patients. $^{1-10}$ The mental deficit appears to be restricted to small subgroups of patients and does not have a significant impact on day to day functioning. These studies, however, have been performed exclusively on selected cohorts of homosexual or bisexual subjects, who represent only a part of the entire HIV population. There are few studies investigating other risk-groups, such as intravenous drug users (IVDU). IVDU represents a special population, in terms of both compliance difficulties and other confounding factors (immunological, socio-cultural, affective and neurobehavioural), which may increase their vulnerability to the effects of the infection. ${ }^{11}$ As such, a different natural history for IVDU may be hypothesized. In particular, it is important to understand whether IVDU present a different pattern and progression of cognitive impairment compared with other risk-groups.

Royal et al. ${ }^{12}$ studied HIV-1 seropositive and seronegative IVDU, who scored significantly lower on neuropsychological tests compared with norms from a cohort of homosexual men. The authors suggest that HIV infection was not the dominant cause of the neurological abnormalities found. This study, however, was confounded by a number of factors including previous head trauma and loss of consciousness in both seropositive and seronegative subjects.

Correspondence to: Dr Giorgio Bono, IRCCS C. Mondino, Via Palestro 3, 27100 Pavia, Italy. 
A longitudinal study ${ }^{13}$ confirmed that chronic intravenous drug use may be associated with increased frequency of neuropsychological abnormalities, although there is no evidence of an interaction with HIV infection to produce additional cognitive impairment. In another followup study seropositive IVDU performed worse than seronegative subjects and no decline over time was detected. ${ }^{14} \mathrm{~A}$ study of an Edinburgh cohort of HIV positive IVDU at different stages of the disease showed significant cognitive impairment only among symptomatic patients (CDC group IV). ${ }^{15,16}$ Finally, in a recent study on seropositive and seronegative detoxified subjects HIV infection per se could not explain the neuropsychological impairment observed. ${ }^{17}$

Previous studies from our group have focused on the interaction between HIV infection and cognitive functioning. Moreover, the selection of homosexual or bisexual asymptomatic subjects was considered a reliable condition to avoid confounding factors. ${ }^{18,19}$ We have found only a slight deficit for verbal memory in a selected population of asymptomatic homosexuals or bisexuals with longitudinal evaluation not showing any change in neuropsychological impairment. However, since $50 \%$ of the entire HIV population in Italy are IVDU, the evaluation and follow-up of this particular group in well-defined experimental conditions represented a relevant reference point for a reliable definition of these cases in the asymptomatic phase, as well as for distinguishing the effects of disease-related versus non-related factors on cognitive performance. Other reasons, mainly epidemiological, sustain the rationale of this research, even if results from previous studies are conclusive. ${ }^{13,14}$ Particular points, however, need to be stressed. First of all, there is a lack of studies on IVDU in Italy. Secondly, as far as the socio-demographic variables are concerned, the Italian IVDU population shows quite different characteristics in comparison to the same population in the United States. In fact, all the subjects belong to the white race and do not present significant variations in cultural conditions. ${ }^{20}$ Moreover, our patients were selected by excluding severe confounding factors, such as pre-existing neurological and psychiatric diseases (in particular head trauma), which may be possible causes of cognitive impairment. ${ }^{21}$ Finally, as far as drug consumption was concerned subjects were observed in homogeneous and controlled conditions.

\section{Subjects}

From January 1992 two groups of IVDU outpatients (46 HIV seronegative and 56 seropositive in the asymptomatic stages of the disease) at the Department of Infectious Diseases, University of Pavia and SERT of Pavia, Italy, were observed. In Italy SERT (Servizio Tossicodipendenze) are the main organizations involved in the care of drug users. General conditions and body mass index were within the normal range. Subjects with a history of severe head trauma, mental retardation, learning disability, previous neurological or psychiatric disorders were excluded from the study.

A preliminary psychiatric interview and Zung's Rating Scales ${ }^{22,23}$ for anxiety and depression were administered before admission to the study in order to exclude patients with psychotic or affective (depression in particular) disorders, according to DSM-III-R criteria. On this basis, nine subjects (four seronegative and five seropositive) were excluded from the study. Informed consent was obtained from all subjects.

The patients recruited ( 42 seronegative and 51 seropositive) were reassessed at 12 months. Three HIV negative subjects and four HIV positive patients did not present at the neuropsychological follow-up. Five subjects from the seropositive group progressed to ARC/AIDS stages. Therefore, after 1 year follow-up the data of 39 seronegative (mean age 28.6 ( \pm 4.9 ) years, sex $\mathrm{m} / \mathrm{f} 30 / 9$, mean educational level 10.1 $( \pm 3.0$ ) years) and 42 seropositive (mean age 27.0 ( \pm 5.3 ) years, sex $\mathrm{m} / \mathrm{f} 31 / 11$, mean educational level 10.9 ( \pm 2.8$)$ years) patients were available. Statistical analysis was performed on these two groups only.

The two groups were comparable with respect to age, sex distribution, years of education and socio-demographic variables.

For drug consumption no statistical difference could be detected between the two groups. About $35 \%$ of seronegative patients and $20 \%$ of seropositive patients were enrolled in a Methadone Maintenance Treatment Programme (MMP). All subjects provided samples twice a week for urine analysis. Urine specimens were collected by members of staff (i.e. nurses) and were screened at a Toxicology Laboratory for the presence of morphine, cannabis, methadone, cocaine and amphetamine. The mean dose of methadone dispensed was $35 \mathrm{mg}$ (range 25$50 \mathrm{mg}$ ). The other subjects, not engaged in 
MMP, reported heroin use about once a week during the last 6 months. Some of these were randomly tested by urine analysis. The pattern of consumption did not change during the followup for these subjects.

The HIV patients who had been selected for the study underwent a standard physical and neurological examination and assessment of the immunological profile every 6 months. All control subjects remained seronegative. In the seropositive group CD4 lymphocyte count was $633 \pm 307$ at baseline and $504 \pm 27$ at 1-year follow-up.

\section{Methods}

Neuropsychological tests were administered at baseline and after 12 months, in different equivalent forms. The following tests were used:

- Digit Symbol (24). This test explores visuomotor and attentive functions. It is a sub-test of WAIS and has been found to be very sensitive to brain damage.

- Trail Making Test A and B (25). This measures psychomotor speed and divided attention. It has been used to test for early HIV-related neuropsychological impairment (12);

- Finger Tapping Test. The Finger Tapping Test is probably the most widely used test for manual dexterity. Five-second trials of the dominant hand are made with a brief rest period between trials. The score is the average of five trials (25);

- Digit span (forward and backward) (24). This test evaluates short-term verbal memory and attention;

- Logical memory (26) (immediate and delayed recall (after $\left.30^{\prime}\right)$ ). This test assesses verbal memory (short and long-term). The difference between immediate and delayed recall is considered as a measure of forgetting;

- Corsi's test (27) which evaluates short-term visuo-spatial memory;

- Visual reproduction (immediate and delayed recall (after $\left.30^{\prime}\right)$ ) (26). This test, a subitem of Wechsler Memory Scale, explores visuo-constructive memory functions. The difference between immediate and delayed recall can be considered as a measure of forgetting;

- Raven's Progressive Matrices 38 (subsets A, B, C, D) (27). This task investigates non verbal intelligence and visuospatial abilities;
- Word Fluency (27). This test explores language processes. It requires the subject to produce. as many words belonging to four semantic categories (fruits, colours, animals and towns) as possible. Two minutes are allowed for each category.

The neuropsychological tests were administered to all subjects under standard conditions, avoiding stress, fatigue and other factors/events influencing mental performance, such as fever. No drug use was admitted within $24 \mathrm{~h}$ before testing sessions.

Administration of all neuropsychological tests took approximately $1 \mathrm{~h}$. The overriding aim in selecting the above instruments was to utilize tests which were easy to complete, had relatively short administration times, were sensitive to acquired impairment and would measure cognitive impairment associated with HIV infection. At 12 months' follow-up Zung's rating scales for anxiety and depression were also administered in order to assess changes in affective status. Analysis of the data was carried out using ANOVA and $\chi^{2}$ tests.

\section{Results}

At baseline no significant differences were detected between seronegative and asymptomatic HIV infected patients for all cognitive measures (Table 1). With respect to the norms for the Italian population, corrected by age, sex and education, $31 \%(n=12)$ of seronegative and $36 \%(n=15)$ of seropositive subjects scored abnormally (2 SD below the mean of controls) on at least two of the neuropsychological measures.

At follow-up after 1 year the cognitive parameters did not show significant changes in either group. In particular, no decline in performance for seropositive and seronegative patients was detected. A slight but non-significant improvement on some neuropsychological measures could be attributable to practice effects. ANOVA analysis of the interaction term group (HIV + I HIV -) by time (baseline/follow-up did not show any significant changes for all cognitive variables examined. The number of subjects who at the baseline scored abnormally on at least two of the neuropsychological measures did not change over time in both groups $\left(\chi^{2}\right.$ test: 0.05 , NS). 
Table 1. Baseline and follow-up neuropsychological evaluation of IVDU patients (mean $\pm S D$ )

\begin{tabular}{|c|c|c|c|c|}
\hline & \multicolumn{2}{|c|}{ Seronegative patients ( $n$ 39) } & \multicolumn{2}{|c|}{ HIV + patients ( $n$ 42) } \\
\hline & 1 st ex. & IInd ex. & 1st èx. & IInd ex. \\
\hline $\begin{array}{l}\text { Digit symbol } \\
\text { Trail Making Test }\end{array}$ & $43.9 \pm 11.4$ & $46.2 \pm 10.3$ & $42.0 \pm 9.9$ & $45.1 \pm 10.4$ \\
\hline Part A & $39.4 \pm 12$ & $37.1 \pm 13$ & $40.4 \pm 12$ & $37.4 \pm 11$ \\
\hline Part B & $104.1 \pm 35$ & $95.6 \pm 31$ & $112.5 \pm 40$ & $99.1 \pm 39$ \\
\hline Finger tapping & $43.7 \pm 8.9$ & $44.1 \pm 8.7$ & $42.1 \pm 7.6$ & $42.0 \pm 7.4$ \\
\hline \multicolumn{5}{|l|}{ Digit span } \\
\hline Forward & $5.6 \pm 0.9$ & $5.4 \pm 0.9$ & $5.9 \pm 1.0$ & $5.7 \pm 1.1$ \\
\hline $\begin{array}{l}\text { Backward } \\
\text { Logical memory }\end{array}$ & $4.1 \pm 0.6$ & $4.3 \pm 0.8$ & $4.1 \pm 0.7$ & $4.0 \pm 0.6$ \\
\hline Immediate rec. & $9.4 \pm 2.5$ & $9.9 \pm 2.2$ & $9.1 \pm 2.1$ & $9.5 \pm 2.4$ \\
\hline Delayed rec. & $8.1 \pm 2.9$ & $9.1 \pm 2.5$ & $7.9 \pm 2.3$ & $8.2 \pm 2.7$ \\
\hline Forgetting \% & 13.8 & 9.1 & 13.2 & 13.7 \\
\hline Corsi & $5.4 \pm 1.0$ & $5.6 \pm 0.9$ & $5.5 \pm 1.1$ & $5.6 \pm 1.0$ \\
\hline \multicolumn{5}{|l|}{ Visual Reproduction } \\
\hline Immediate rec. & $11.7 \pm 2.6$ & $11.8 \pm 2.5$ & $10.9 \pm 2.1$ & $11.2 \pm 3.4$ \\
\hline Delayed rec. & $10.5 \pm 2.0$ & $10.7 \pm 2.0$ & $9.8 \pm 2.9$ & $10.1 \pm 3.9$ \\
\hline Forgetting \% & 10.2 & 9.3 & 9.1 & 9.8 \\
\hline Raven & $34.5 \pm 4.6$ & $35.2 \pm 4.8$ & $33.7 \pm 5.2$ & $34.9 \pm 5.5$ \\
\hline Word fluency & $19.6 \pm 4.1$ & $20.2 \pm 3.9$ & $18.9 \pm 4.3$ & $19.3 \pm 3.7$ \\
\hline
\end{tabular}

Among the HIV-infected group antiretroviral therapy (AZT) was administered in nine cases who presented with a persistently low $\left(<400 \times 10^{6}\right.$ 1) CD4 lymphocyte count, but without presence of clinical progression. No evident effect on cognitive parameters was observable in comparison with the other cases.

\section{Conclusions}

Results here show that HIV seropositive IVDU do not differ significantly from HIV negative drug users on a range of cognitive tests. Comparisons of these two groups with Italian population norms suggest some degree of impairment. The neuropsychological evaluation showed the presence of slight cognitive deficits for attention, speed of processing of information (Trail Making $A$ and $B$ ) and verbal memory (Digit span and Logic Memory). The percentage of subjects who scored abnormally on at least two neuropsychological tests were lower than those reported by Royal et al. ${ }^{12}$ This may be attributable to the more restrictive selection criteria (patients with head trauma were excluded) utilized in the present study.

A wide range of neuropsychological deficits (impaired memory and psychomotor speed) is reported to be associated with substance abuse. ${ }^{28}$ Moreover, the active substance abuse and the life-style that drug abuse involves (possible loss of consciousness due to drug consumption, infective complications, poor social relationships) may favour the presence of subclinical nervous system disorders.

The comparison of the cognitive performance of IVDU with other HIV risk-groups, such as homosexuals, is difficult because of different socio-demographic variables and different neuropsychological methods employed. In the study by Royal et al. ${ }^{12}$ drug abusers performed significantly lower when compared with norms established for a cohort of homosexuals. In previous studies, ${ }^{18,19}$ asymptomatic homosexuals showed only slight impairment on verbal memory, while other cognitive functions were preserved. It must be stressed, however, that previously studied homosexual subjects generally belong to self-selected, highly educated and motivated groups, while IVDU present different characteristics (e.g. lower educational level, different sex distribution and very poor compliance rates). Further research is needed to detect specific neuropsychological differences among IVDU and homosexuals, using appropriate control groups.

In accordance with previous studies, ${ }^{13}, 14$ longitudinal evaluation showed no progression from baseline mild cognitive abnormalities in both seropositive and seronegative subjects, in 
the absence of significant clinical changes. The slight decline in CD4 count in seropositive subjects was not related to a worsening of cognitive functions. This is consistent with recent findings, which have shown that CD4 levels do not predict the presence or degree of neuropsychological disturbance in the early stages of HIV infection. ${ }^{29}$ Also, longitudinal studies in asymptomatic homosexuals have failed to reveal a gradual decline in neuropsychological performance. ${ }^{30}$ Therefore, results from this study confirm previous studies which suggest that the cognitive impairment in asymptomatic IVDU may not be directly related to HIV infection. However, at least in small groups the neuropsychological deficit might be, in the absence of severe confounding factors, the result of the interaction between variables related to substance abuse and other factors related or unrelated to HIV infection.

\section{Acknowledgements}

This work was supported by Ministero SanitaISS Grant AIDS Project II and III.

\section{References}

1. Grant, I., Atkinson, J. H., Hesselink, J. R. et al. (1987) Evidence for early central nervous system involvement in the acquired immunodeficiency syndrome (AIDS) and other human immunodeficiencies virus (HIV) infections. Studies with neuropsychological testing and magnetic resonance imaging, Annals of Internal Medicine, 107, 828-836.

2. Goethe, K. E., Mitchell, J. E., Marshali, D. W. et al. (1989) Neuropsychological and neurological function of human immunodeficiency virus seropositive asymptomatic individuals, Archives of Neurology, 46, 129-133.

3. Janssen, R. S., Saykin, A. J., Cannon, L. et al. (1989) Neurological and neuropsychological manifestations of HIV-1 infection: association with AIDS-related complex but not asymptomatic HIV-1 infection, Annals of Neurology, 26, 592-600.

4. McArthur, J. C., Cohen, B. A., Selnes, O. A. et al. (1989) Low prevalence of neurological and neuropsychological abnormalities in otherwise healthy HIV-1 infected individuals: results from the Multicenter AIDS Cohort Study, Annals of Neurology, 26, 601-611.

5. WiLkie, F. L., Eisdorfer, C., Morgan, R., Lowenstein, D. A. \& Szapcznik, J. (1990) Cognition in early human immunodeficiency virus infection, Archives of Neurology, 47, 433-440.

6. Miller, E. N., Selnes, O. A., McArthur, J. C. et al. (1990) Neuropsychological performance in
HIV-1-infected homosexual men: the Multicenter AIDS Cohort Study (MACS), Neurology, 40, 197203.

7. Miller, E. N., Satz, P. \& Visscher, B. (1990) Computerized and conventional neuropsychological assessment of HIV-1-infected homosexual men, Neurology, 41, 1608-1616.

8. Stern, Y., MARder, K., Bell, K. et al. (1991) Multidisciplinary baseline assessment of homosexual men with and without human immunodeficiency virus infection. Neurologic and neuropsychological findings, Archives of General Psychiatry, 48, 131-138.

9. Bornstein, R. A., Nasrallah, H. A., Para, $M$ F., Fass, R. J., Whitacre, C. C. \& RiCE, R. R. (1992) Neuropsychological performance in asymptomatic HIV infection, fournal of Neuropsychiatry and Clinical Neurosciences, 4, 386-394.

10. MCAlister, R. H., HeRns, M. V., Harrison, M. J. G. et al. (1992) Neurological and neuropsychological performance in HIV seropositive men without symptoms, fournal of Neurology, Neurosurgery, Psychiatry, 55, 143-148.

11. Weber, R., Ledegueber, B. \& Opravil, $M$. (1990) Progression of HIV infection in misusers of injected drugs who stop injecting or follow a programme of maintenance with methadone, British Medical fournal, 301, 1362-1365.

12. Royal, III W., Updike, M., Selnes, O. A. et al. (1991) HIV-1 infection and nervous system abnormalities among a cohort of intravenous drug users, Neurology, 41, 1905-1910.

13. Selnes, O. A., McArthur, J. C., Royal, III W. et al. (1992) HIV-1 infection and intravenous drug users: longitudinal neuropsychological evaluation of asymptomatic subjects, Neurology, 42, 1924 1930.

14. MCKegney, F. P., O’Dowd, M. A., Fenner, C., Selwyn, P., Drucker, E. \& Friedland, G. H. (1990) A prospective comparison of neuropsychologic function in HIV-seropositive and seronegative methadone-maintained patients, $A I D S, 4$, 565-569.

15. Egan, G. V., Crawford, J. R., Brettle, R. P. \& GoodwIN, G. M. (1990) The Edinburgh Cohort of HIV-positive drug users: current intellectual function is impaired, but not due to early AIDS dementia complex, AIDS, 4, 651-656.

16. Egan, G. V., Brettle, R. P. \& Goodwin, G. M. (1992) The Edinburgh Cohort of HIV-positive drug users: pattern of cognitive impairment in relation to progression of disease, British fournal of Psychiatry, 161, 522-531.

17. Hestad, K., Aukrust, P., Ellersten, B., Klove, H. \& WILberG, K. (1993) Neuropsychological deficits in HIV-1 seropositive and seronegative intravenous drug users, foumal of Clinical and Experimental Neuropsychology, 15, 732-742.

18. Sinforiani, E., Mauri, M., Bono, G., MuraTORI, S., Alessi, E. \& Minoli, L. (1991) Cognitive abnormalities and disease progression in a selected population of asymptomatic HIV-positive subjects, $A I D S$, 5, 1117-1120. 
19. MaUri, M., Sinforiani, E., Muratori, S., ZerBONI, R. \& Bono, G. (1993) Three-year neuropsychological follow-up in a selected group of HIV-infected homosexual-bisexual men, AIDS, 7, 241-245.

20. STERN, Y. (1994) Neuropsychological assessment of seropositive intravenous drug users, in: GRANT, I. \& MARTIN, A. (Eds) Neuropsychology of HIVInfection, pp. 220-233 (New York, Oxford University Press).

21. WILKINS, J. W., Robertson, K. R., VAN DER Horst, C. et al. (1990) The importance of confounding factors in the evaluation of neuropsychological changes in patients infected with human immunodeficiency virus, fournal of AIDS, 3, 938942.

22. ZUNG, W. K. (1965) A self-rating depression scale, Archives of General Psychiatry, 12, 63-70.

23. ZUNG, W. K. (1980) How Normal is Anxiety? (Current Concepts) (London, Upjohn Company).

24. Wechsler, D. (1958) The Measurement and $A p$ praisal of Adult Intelligence, 4th edn (Baltimore, Williams and Wilkins).
25. LEZAK, M. (1983) Neuropsychological Assessment (New York, Oxford University Press).

26. WECHSLER, D. (1945) A standardized memory scale for clinical use, fourmal of Psychology, 19, 87-94.

27. Gruppo Italiano per lo Studio NeuropsicoLOGICO DELL'INVECCHIAMENTO (1988) Taratura Italiana di Test Neuropsicologici, Italian foumal of Neurological Science, 7 (Suppl. 8), 1-120.

28. SWeeney, J. A., Meisel, L., Walsh, V. L. \& CAstrovinci, D. (1989) Assessment of cognitive functioning in poly-substance abusers, foumal of Clinical Psychology, 45, 346-351.

29. Poaraza, A. M., Bornstein, R. A., Whitacre, C. C. et al. (1994) Neuropsychological performance and CD4 levels in HIV-1 asymptomatic infection, fournal of Clinical and Experimental Neuropsychology, 16, 777-783.

30. Selnes, O. A., Miller, E., McArthur, J. et al. (1990) HIV-1 infection: no evidence of cognitive decline during the asymptomatic stages, Neurology, 40, 204-208. 
This document is a scanned copy of a printed document. No warranty is given about the accuracy of the copy. Users should refer to the original published version of the material. 